\title{
Relationship between core stability and dynamic balance in women with postmenopausal osteoporosis
}

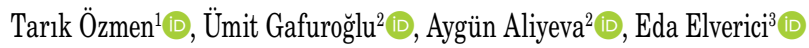 \\ ${ }^{1}$ Department of Physiotherapy and Rehabilitation, Faculty of Health Sciences, Karabük University, Karabük, Turkey \\ ${ }^{2}$ Department of Physical Medicine and Rehabilitation, Ankara Numune Training and Research Hospital, Ankara, Turkey \\ ${ }^{3}$ Department of Radiology, Ankara Numune Training and Research Hospital, Ankara, Turkey
}

Received: May 08, 2017 Accepted: September 12, 2017 Published online: 0ctober 06, 2017

\begin{abstract}
Objectives: The aim of this study was to investigate the relationship between core stability and dynamic balance in women with postmenopausal osteoporosis.

Patients and methods: A total of 100 females (mean age 59.9 \pm 7.5 years; range, 42 to 73 years) with postmenopausal osteoporosis between January 2016 and June 2016 were included in this study. All patients were evaluated for dynamic balance with the Star Excursion Balance Test (SEBT) and for core stability with trunk flexion, extension, and Side Bridge Test (SBT).

Results: There was a significant correlation between age and the reach directions of anterior (A), posteromedial (PM), and posterolateral $(\mathrm{PL})$ of the right limb $(\mathrm{p}<0.001, \mathrm{p}=0.009, \mathrm{p}=0.012)$ and the reach directions of $\mathrm{A}$ and $\mathrm{PM}$ of the left limb $(\mathrm{p}<0.001, \mathrm{p}=0.004)$. There was no correlation between the lumbar spine, femoral neck, and total hip Bone Mineral Density (BMD) and the reach directions of SEBT ( $\mathrm{p}>0.05$ ). There was a significant correlation between the trunk flexion test results and the reach directions of $A, P M$, and PL of the right limb ( $\mathrm{p}=0.005$, $\mathrm{p}=0.001, \mathrm{p}=0.002),(\mathrm{r}=0.277, \mathrm{r}=0.333, \mathrm{r}=0.308)$ and the reach directions of $\mathrm{A}, \mathrm{PM}$, and PL of the left limb $(\mathrm{p}=0.008, \mathrm{p}=0.016, \mathrm{p}=0.005)$, $(r=0.265, r=0.239, r=0.276)$. There was a significant correlation between the SBT results and the reach directions of A, PM, and PL of the right $\operatorname{limb}(\mathrm{p}<0.001, \mathrm{p}<0.001, \mathrm{p}=0.005),(\mathrm{r}=0.423, \mathrm{r}=0.366, \mathrm{r}=0.281)$ and the reach directions of $\mathrm{A}, \mathrm{PM}$, and $\mathrm{PL}$ of the left limb $(\mathrm{p}<0.001, \mathrm{p}<0.001$, $\mathrm{p}=0.001),(\mathrm{r}=0.418, \mathrm{r}=0.356, \mathrm{r}=0.316)$. There was a significant correlation between the trunk extension test results and the reach directions of A, PM, and PL of the right limb ( $<<0.001, \mathrm{p}<0.001, \mathrm{p}=0.006),(\mathrm{r}=0.383, \mathrm{r}=0.471, \mathrm{r}=0.276)$ and the reach directions of $\mathrm{A}, \mathrm{PM}$, and PL of the left limb ( $\mathrm{p}<0.001, \mathrm{p}<0.001, \mathrm{p}=0.003)(\mathrm{r}=0.407, \mathrm{r}=0.401, \mathrm{r}=0.297)$.
\end{abstract}

Conclusion: Our study results showed that age and core stability were associated with dynamic balance in women with postmenopausal osteoporosis.

Keywords: Balance; core stability; osteoporosis.

Osteoporosis is a systemic skeletal disease characterized by decreased bone mass, microarchitectural deterioration of the bone tissue leading to enhanced bone fragility, and a consequent increase in the fracture risk. ${ }^{[1]}$ Vertebrae and hip fractures are associated with a significant mortality and morbidity rate, and low quality of life in patients with osteoporosis. ${ }^{[2,3]}$ Although osteoporosis does not directly affect the muscle strength, previous studies have shown that low Bone Mineral Density (BMD) may be associated with back extensor muscle weakness in patients with osteoporosis. ${ }^{[4-6]}$ Lumbar kyphosis angle, back extensor muscle strength, and paravertebral muscle thickness at the lumbar spine are also correlated with spinal mobility in patients with osteoporosis ${ }^{[6]}$ In a study, Sinaki et al ${ }^{[7]}$ reported that the women with osteoporosis and hyperkyphosis had loss of back extensor and leg muscles strength, slower gait, and inadequate balance resulting in a tendency to fall.

The core has been described as a muscular cylinder with the abdominals in the front, erector spinae and gluteal muscles in the back, the diaphragm as the roof, and the pelvic floor and hip girdle musculature in the bottom. ${ }^{[8]}$ The core is the center of the functional kinetic chain, providing the proximal stability for the

Corresponding author: Tarık Özmen, MD. Karabük Üniversitesi Sağlık Bilimleri Fakültesi, Fizyoterapi ve Rehabilitasyon Anabilim Dall, 78050 Karabük, Turkey. e-mail: tarikozmen@karabuk.edu.tr 
distal mobility and function of the limbs. ${ }^{[9]}$ It has been reported that core muscle fatigue decreases dynamic stability of the trunk, thereby, leading to loss of balance control. ${ }^{[10,11]}$

Falls are the most common cause of fractures in women with postmenopausal osteoporosis. ${ }^{[12,13]}$ Identifying the factors influencing postural balance is critical for the quality of life in women with postmenopausal osteoporosis. In the present study, we aimed to investigate the relationship between core muscle endurance and dynamic balance in women with postmenopausal osteoporosis.

\section{PATIENTS AND METHODS}

A total of 100 women with postmenopausal osteoporosis (mean age $59.9 \pm 7.5$ years; range, 42 to 73 years) who were admitted to the Physical Medicine and Rehabilitation outpatient clinics at Ankara Numune Training and Research Hospital between January 2016 and June 2016 were included in the study. Participants who had a history of musculoskeletal, neurological, or orthopedic disorders that might have affected their ability to perform dynamic balance and core stability tests were excluded from the study. Data including age at menarche and menopause were recorded. Body mass index was calculated as weight in kilograms divided by height in meters squared $\left(\mathrm{kg} / \mathrm{m}^{2}\right)$.

The study was approved by the Ankara Numune Training and Research Hospital Ethics Committee (523/2015) and a written consent was obtained from each patient. The study was conducted in accordance with the principles of the Declaration of Helsinki.

\section{Measurement of bone mineral density}

The bone mineral density of the lumbar spine, femoral neck, and total hip was measured with dual-energy X-ray absorptiometry (DEXA; Hologic Discovery A, Waltham, MA, USA). According to the data from World Health Organization (WHO), values of $-2.5 \mathrm{~g} / \mathrm{cm}^{2}$ and lower for the total lumbar, total femur, or femoral neck T-score were accepted as indicators of osteoporosis. ${ }^{[14]}$

\section{Dynamic balance}

The dynamic balance was evaluated using the Star Excursion Balance Test (SEBT). In general, the eight directions of the SEBT are used in athletes and young individuals. ${ }^{[15-17]}$ In the present study, however, we used three reach directions, as it required the shortest time for clinical use. ${ }^{[18]}$ The reach directions were determined by affixing three tape measures to the floor, one orientated anterior $(\mathrm{A})$ to the apex and two aligned at $135^{\circ}$ to this in the posteromedial (PM) and posterolateral (PL) directions. Each patient was instructed to reach as far as possible with the other leg in each of the three directions, while single-leg stance (Figure 1). The reach distances from three trials in each direction were calculated using the following formula: ${ }^{[18]}$

\section{(Maximized excursion distance/Leg length) $\times 100$}

The length of the leg was measured from the anterior superior iliac spine to the ipsilateral medial malleolus with a standard tape measure in the supine position on the treatment table. ${ }^{[19]}$

\section{Core stability}

The protocol established by McGill ${ }^{[20]}$ was used to identify core muscle endurance. In the side bridge test (SBT), the patients were asked to lay on their side with their legs extended on a bed, resting on their forearm with the elbow flexed to $90^{\circ}$. They were also instructed to lift the hip off the table with the other arm and hand across the chest resting on the opposite shoulder. The test was terminated, when the straight body position could no longer be maintained. Time was recorded in seconds using a stopwatch. In the Trunk Flexion Test (TFT), the patients were seated with their back resting against a wedge that maintained $45^{\circ}$ flexion from the horizontal on the treatment table. Knees were flexed

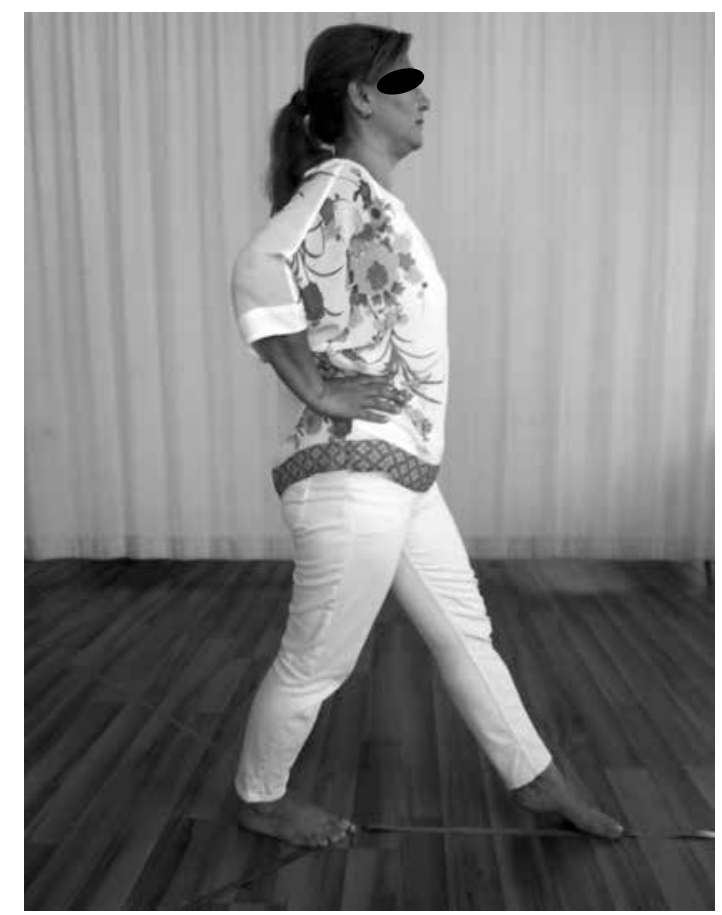

Figure 1. Star Excursion Balance Test. 


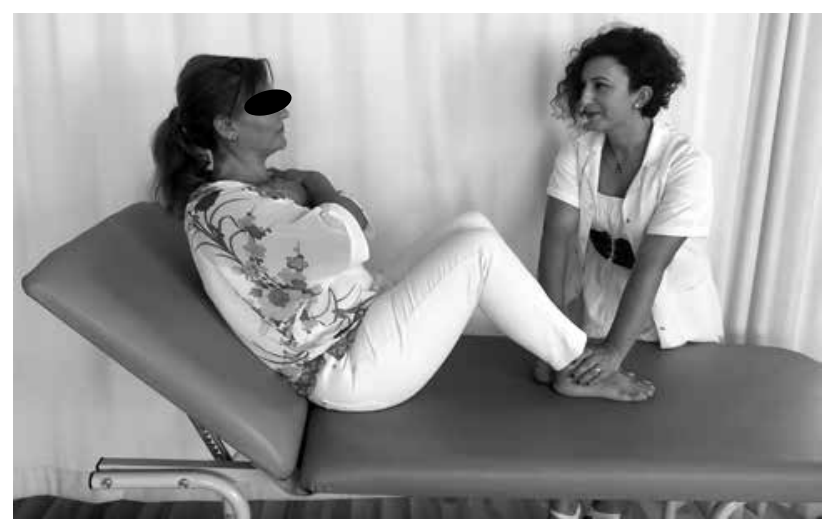

Figure 2. Trunk Flexion Test.

to $90^{\circ}$ and the feet stabilized by the researcher. The test was terminated, when the upper body could no longer remain at the $45^{\circ}$ angle. Time was recorded in seconds using a stopwatch (Figure 2). In the Trunk Extension Test (TET), the patients were asked to lay on the treatment table in a prone position with the upper body cantilevered out over the end of the table. They were asked to maintain a horizontal body position with arms crossed across the chest while the researcher stabilized the lower extremities. The test was terminated, when the patient fell below the horizontal position. Time was recorded in seconds using a stopwatch (Figure 3).

\section{Statistical analysis}

Statistical analysis was performed using the SPSS version 16.0 software (SPSS Inc., Chicago,

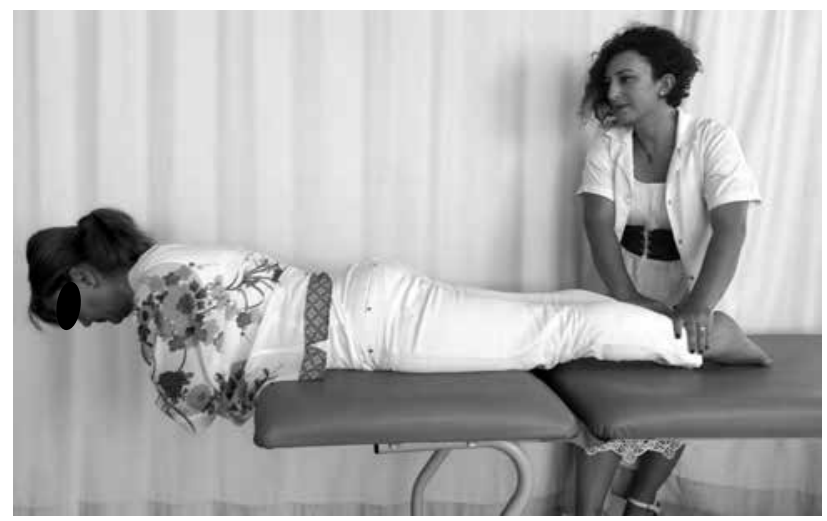

Figure 3. Trunk Extension Test.

IL, USA). Descriptive statistics were expressed in mean \pm standard deviation (SD). The relevance of data to a normal distribution was evaluated using the Shapiro-Wilk test. The relationship between the study parameters was assessed using the Pearson's correlation analysis (r) or Spearman's rho correlation analysis (rs) for normally or non-normally data, respectively. The correlation coefficient values were defined as follows: very strong correlation $(\geq 0.8)$; moderately strong correlation (0.6-0.8); fair correlation $(0.3-0.5)$, and poor correlation $(\leq 0.3) \cdot{ }^{[21]}$ A $p$ value of $<0.05$ was considered statistically significant.

\section{RESULTS}

Demographic characteristics of the participants and correlation analyses are presented in Table 1

Table 1. Demographic and clinical characteristics of patients

\begin{tabular}{lccc}
\hline Variables & Mean \pm SD & Median & Min-Max \\
\hline Age (year) & $59.9 \pm 7.5$ & 58 & $42-73$ \\
Age at menarche (year) & $13.5 \pm 1.6$ & 13 & $11-20$ \\
Age at menopause (year) & $46.0 \pm 4.9$ & 47 & $26-55$ \\
Body Mass Index $\left(\mathrm{kg} / \mathrm{m}^{2}\right)$ & $28.6 \pm 4.8$ & 28 & $18-42$ \\
Femoral neck BMD $\left(\mathrm{g} / \mathrm{cm}^{2}\right)$ & $0.6 \pm 0.1$ & 0.63 & $0.41-0.82$ \\
Total hip BMD $\left(\mathrm{g} / \mathrm{cm}^{2}\right)$ & $0.8 \pm 0.1$ & 0.79 & $0.48-1.00$ \\
Anteroposterior lumbar spine (L1-L4) BMD $\left(\mathrm{g} / \mathrm{cm}^{2}\right)$ & $0.7 \pm 0.1$ & 0.72 & $0.58-0.86$ \\
Lateral lumbar spine (L2-L3) BMD $\left(\mathrm{g} / \mathrm{cm}^{2}\right)$ & $0.5 \pm 0.1$ & 0.51 & $0.36-0.75$ \\
Core stability & & & \\
Side bridge test (s) & $14.7 \pm 1.28$ & 13.50 & $0-45$ \\
Trunk flexion test (s) & $36.2 \pm 2.3$ & 38 & $0-84$ \\
Trunk extension test (s) & $29.7 \pm 2.1$ & 30 & $0-80$ \\
Dynamic balance (SEBT) & & & \\
Anterior (right) $(\mathrm{cm})$ & $45.1 \pm 11.3$ & 45 & $15-73$ \\
Posteromedial (right) (cm) & $46.0 \pm 10.3$ & 47 & $12-83$ \\
Posterolateral (right) (cm) & $33.9 \pm 8.7$ & 34 & $9-54$ \\
Anterior (left) (cm) & $45.3 \pm 10.5$ & 47.5 & $15-70$ \\
Posteromedial (left) $(\mathrm{cm})$ & $45.4 \pm 9.9$ & 47 & $10-70$ \\
Posterolateral (left) $(\mathrm{cm})$ & $33.2 \pm 8.4$ & 34 & $9-50$ \\
\hline
\end{tabular}

SD: Standard deviation; BMD: Bone Mineral Density; SEBT: Star Excursion Balance Test. 
Table 2. Correlations between dynamic balance and other variables

\begin{tabular}{|c|c|c|c|c|c|c|}
\hline Variables & A (right) & PM (right) & PL (right) & A (left) & PM (left) & PL (left) \\
\hline \multicolumn{7}{|l|}{ Age } \\
\hline $\mathrm{p}$ & 0.000 & 0.009 & 0.012 & 0.000 & 0.004 & 0.234 \\
\hline $\mathrm{r}$ & -0.376 & -0.260 & -0.250 & -0.372 & -0.284 & -0.120 \\
\hline \multicolumn{7}{|c|}{ Age at menopause } \\
\hline $\mathrm{p}$ & 0.561 & 0.540 & 0.296 & 0.515 & 0.236 & 0.583 \\
\hline $\mathrm{r}_{\mathrm{s}}$ & -0.059 & -0.062 & 0.106 & -0.066 & -0.120 & -0.056 \\
\hline \multicolumn{7}{|c|}{ Body Mass Index } \\
\hline $\mathrm{p}$ & 0.070 & 0.072 & 0.172 & 0.262 & 0.074 & 0.061 \\
\hline $\mathrm{r}$ & -0.182 & $0 .-181$ & -0.138 & -0.113 & -0.180 & -0.188 \\
\hline \multicolumn{7}{|c|}{ Femoral neck BMD } \\
\hline $\mathrm{p}$ & 0.864 & 0.981 & 0.788 & 0.618 & 0.904 & 0.178 \\
\hline $\mathrm{r}$ & -0.017 & 0.002 & -0.027 & -0.051 & 0.012 & -0.136 \\
\hline \multicolumn{7}{|c|}{ Total hip BMD } \\
\hline $\mathrm{p}$ & 0.464 & 0.807 & 0.722 & 0.521 & 0.983 & 0.283 \\
\hline $\mathrm{r}$ & 0.074 & -0.025 & -0.036 & 0.065 & -0.002 & -0.108 \\
\hline \multicolumn{7}{|c|}{ Anteroposterior Lumbar spine BMD (L1-L4) } \\
\hline $\mathrm{p}$ & 0.592 & 0.115 & 0.086 & 0.955 & 0.361 & 0.350 \\
\hline $\mathrm{r}_{\mathrm{s}}$ & -0.054 & -0.159 & -0.173 & 0.006 & -0.092 & -0.094 \\
\hline \multicolumn{7}{|c|}{ Lateral Lumbar spine BMD (L2-L3) } \\
\hline $\mathrm{p}$ & 0.451 & 0.316 & 0.398 & 0.560 & 0.576 & 0.124 \\
\hline $\mathrm{r}$ & -0.076 & -0.101 & -0.085 & -0.059 & -0.057 & -0.155 \\
\hline \multicolumn{7}{|c|}{ Trunk flexion test } \\
\hline $\mathrm{p}$ & 0.005 & 0.001 & 0.002 & 0.008 & 0.016 & 0.005 \\
\hline $\mathrm{r}$ & 0.277 & 0.333 & 0.308 & 0.265 & 0.239 & 0.276 \\
\hline \multicolumn{7}{|c|}{ Side bridge test } \\
\hline $\mathrm{p}$ & 0.000 & 0.000 & 0.005 & 0.000 & 0.000 & 0.001 \\
\hline $\mathrm{r}$ & 0.423 & 0.366 & 0.281 & 0.418 & 0.356 & 0.316 \\
\hline \multicolumn{7}{|c|}{ Trunk extension test } \\
\hline $\mathrm{p}$ & 0.000 & 0.000 & 0.006 & 0.000 & 0.000 & 0.003 \\
\hline $\mathrm{r}$ & 0.383 & 0.471 & 0.276 & 0.407 & 0.401 & 0.297 \\
\hline
\end{tabular}

A: Anterior; PM: Posteromedial; PL: Posterolateral; BMD: Bone Mineral Density; r: Pearson’s Correlation; rs: Spearman's rho correlation.

and Table 2, respectively. The Pearson's correlation analysis showed that there was a negative poor to fair correlation between the age and the reach directions of A $(r=-0.376, p<0.001), P M(r=-0.260, p=0.009)$, and PL $(r=-0.250, p=0.012)$ of the right limb and the reach directions of $\mathrm{A}(\mathrm{r}=-0.372, \mathrm{p}<0.001)$ and $\mathrm{PM}(\mathrm{r}=-0.284, \mathrm{p}=0.004)$ of the left limb. There was no correlation between the anteroposterior lumbar spine (L1-4), lateral lumbar spine (L2-3), femoral neck, and total hip BMD and the reach directions of the SEBT $(p>0.05)$. According to the Pearson's correlation analysis, there was a significant poor to fair correlation between the reach directions of $\mathrm{A}, \mathrm{PM}$, and PL of the right limb $(\mathrm{p}=0.005, \mathrm{p}=0.001, \mathrm{p}=0.002)$, $(r=0.277, r=0.333, r=0.308)$, the reach directions of the left limb $(p=0.008, p=0.016, p=0.005),(r=0.265$, $\mathrm{r}=0.239, \mathrm{r}=0.276$ ), and the TFT results. Also, there was a significant poor to fair correlation between the reach directions of $\mathrm{A}, \mathrm{PM}$, and $\mathrm{PL}$ of the right $\operatorname{limb}(\mathrm{p}<0.001, \mathrm{p}<0.001, \mathrm{p}=0.005), \quad(\mathrm{r}=0.423$, $\mathrm{r}=0.366, \mathrm{r}=0.281$ ), the reach directions of $\mathrm{A}, \mathrm{PM}$, and PL of the left limb $(\mathrm{p}<0.001, \mathrm{p}<0.001, \mathrm{p}=0.001)$, $(\mathrm{r}=0.418, \mathrm{r}=0.356, \mathrm{r}=0.316)$, and the SBT results. Additionally, there was a significant poor to fair correlation between the reach directions of $\mathrm{A}, \mathrm{PM}$, and PL of the right limb $(\mathrm{p}<0.001, \mathrm{p}<0.001, \mathrm{p}=0.006)$, $(r=0.383, r=0.471, r=0.276)$, the reach directions of $A$, $\mathrm{PM}$, and PL of the left limb $(\mathrm{p}<0.001, \mathrm{p}<0.001, \mathrm{p}=0.003)$ $(\mathrm{r}=0.407, \mathrm{r}=0.401, \mathrm{r}=0.297)$ and the TET results. Dynamic balance was also positively correlated with the core muscle endurance.

\section{DISCUSSION}

The findings of our study showed that the dynamic balance was negatively correlated with age in women with postmenopausal osteoporosis. The dynamic balance was disturbed with increasing age. The dynamic balance was evaluated with the SEBT in our study. The SEBT performance depends on kinetic and kinematic factors, such as the range of motion of the knee and hip joints, flexibility, and strength of the lower extremity muscles. ${ }^{[22,23]}$ High inter-tester and intra-tester reliability of the SEBT have previously 
been reported. ${ }^{[19]}$ To the best of our knowledge, there is a limited number of studies that SEBT was used in osteoporosis as an assessment tool for dynamic balance. ${ }^{[24,25]}$

It is well-known that both muscle mass and strength decline with age. ${ }^{[26]}$ Back muscle strength has been reported to decrease by about $50.4 \%$ in females between the ages of 50 and 80 years, which corresponds to about 2.5\% per year. ${ }^{[27]}$ Aging-related decrease in the muscle strength and flexibility may lead to balance impairment in women with postmenopausal osteoporosis. However, postural control and balance depends on the integration of neural and musculoskeletal systems. The proprioceptive, visual, and vestibular centers provide afferent information to the central nervous system and adequate muscle response generated in the trunk and lower extremities. However, the functions of these systems decrease over time. ${ }^{[28,29]}$

Another result of our study is that there was no relationship between the anteroposterior lumbar spine (L1-4), lateral lumbar spine (L2-3), femoral neck and total hip BMD, and the dynamic balance in the women with postmenopausal osteoporosis. However, we were unable to evaluate other confounding factors such as vitamin D and estrogen levels. Previous studies reported that women with osteoporosis had a higher balance instability, compared to those with normal BMD. ${ }^{[30,31]}$ Hammar et al. ${ }^{[32]}$ showed that estrogen replacement increased balance performance measured by dynamic posturography. Gunend and Demirsoy ${ }^{[33]}$ compared postural balance in women with and without postmenopausal osteoporosis and evaluated dynamic balance with Timed Up and Go (TUG) test, Four Square Step Test, and Berg Balance Scale. The authors found no significant difference in the balance between women with and without postmenopausal osteoporosis. Similarly, Korkmaz et al. ${ }^{[34]}$ found no significant difference between the total lumbar and femur T-scores and the balance test scores in women with postmenopausal osteoporosis. They reported that the factors other than BMD such as vitamin D levels might lead to loss of balance in postmenopausal osteoporosis. Also, Hita-Contreras et al. ${ }^{[35]}$ reported postural instability in women with postmenopausal osteoporosis with a BMI of $\geq 25 \mathrm{~kg} / \mathrm{m}^{2}$.

Several studies reported that the muscle strength and balance in older age was associated with osteoporosis. Granacher et al. ${ }^{[36]}$ found a significant relationship between the muscle strength of the trunk flexor, extensor, and rotator and balance performance in older adults. Also, Emilio et al. ${ }^{[37]}$ reported that dynamic balance and lumbar strength were positively associated with the balance ability and risk of falls in older adults. Additionally, a study conducted by Sinaki ${ }^{[7]}$ showed that back extensor strength played an important role in reducing body sway and risk of falls in females with osteoporosis. Korkmaz et al. ${ }^{[34]}$ also suggested a strong negative association between the balance scores and the back extensor and hip flexor muscle strengths in patients with postmenopausal osteoporosis, compared to healthy controls, as assessed by the TUG test and the Berg Balance Scale. Although there was no control group without osteoporosis in our study, our study had a larger sample size than the aforementioned studies. In addition, the participants were evaluated with the TET, TFT, and SBT, but not only the back extensor strength.

In the literature, there are very few studies investigating the association between the core muscle endurance and dynamic balance in elderly people. Suri et al. ${ }^{[38]}$ suggested that the trunk extension endurance and strength were associated with mobility and balance in older adults. Cunha-Henriques et al. ${ }^{[39]}$ showed that the trunk flexor and extensor strength in females with osteoporosis were significantly lower than that of the females without osteoporosis. However, there was no significant difference in the static balance between females with and without osteoporosis. However, dynamic balance was at lower level in $86 \%$ of the females with osteoporosis and $78 \%$ of the females without osteoporosis.

Furthermore, previous studies assessed the isometric muscle strength in patients with postmenopausal osteoporosis, particularly back strength. ${ }^{[39-42]}$ In the present study, the relationship between the core muscle endurance and dynamic balance was investigated, as we hypothesized that the evaluation of the core muscle endurance would be more suitable in determining the relationship between core muscles and dynamic balance in women with postmenopausal osteoporosis. Core muscle endurance tests may be considered as troublesome for older adults. However, several studies support that these tests can be used for women with postmenopausal osteoporosis. ${ }^{[38,42,43]}$ In our study, the participants well tolerated all tests. We also showed that as the core stability decreased, their dynamic balance was deteriorated. These findings suggest that improving trunk endurance is one of the main goals of balance control.

The limitation of this study is that there was no control group without osteoporosis. However, our sample size is larger than previous studies. ${ }^{[7,34,39]}$ In the 
future, further controlled studies on this subject can be planned.

In conclusion, our study results show that the core stability is partially associated with dynamic balance in women with postmenopausal osteoporosis, and age is related to dynamic balance. Therefore, improving the core muscle endurance in women with postmenopausal osteoporosis may contribute to the ability of the dynamic balance.

\section{Declaration of conflicting interests}

The authors declared no conflicts of interest with respect to the authorship and/or publication of this article.

\section{Funding}

The authors received no financial support for the research and/or authorship of this article.

\section{REFERENCES}

1. Downey PA, Siegel MI. Bone biology and the clinical implications for osteoporosis. Phys Ther 2006;86:77-91.

2. Johnell O, Kanis J. Epidemiology of osteoporotic fractures. Osteoporosis Int 2005;16:3-7.

3. Hallberg I, Rosenqvist AM, Kartous L, Löfman O, Wahlström O, Toss G. Health-related quality of life after osteoporotic fractures. Osteoporosis Int 2004;15:834-41.

4. Iki M, Saito Y, Dohi Y, Kajita E, Nishino H, Yonemasu K, et al. Greater trunk muscle torque reduces postmenopausal bone loss at the spine independently of age, body size, and vitamin D receptor genotype in Japanese women. Calcif Tissue Int 2002;71:300-7.

5. Taskiran OO, Tas N, Meray J. The relationship of isokinetic trunk flexor and extensor strength with osteoporosis in older women. Turkish J Phys Med and Rehab 2012;58:272-7.

6. Miyakoshi N, Hongo M, Maekawa S, Ishikawa Y, Shimada Y, Okada K, et al. Factors related to spinal mobility in patients with postmenopausal osteoporosis. Osteoporos Int. 2005;16:1871-4.

7. Sinaki M, Brey RH, Hughes CA, Larson DR, Kaufman KR. Balance disorder and increased risk of falls in osteoporosis and kyphosis: significance of kyphotic posture and muscle strength. Osteoporos Int 2005;16:1004-10.

8. Akuthota V, Ferreiro A, Moore T, Fredericson M. Core stability exercise principles. Curr Sports Med Rep 2008;7:39-44.

9. Kibler WB, Press J, Sciascia A. The role of core stability in athletic function. Sports Med 2006;36:189-98.

10. Davidson BS, Madigan ML, Nussbaum MA. Effects of lumbar extensor fatigue and fatigue rate on postural sway. Eur J Appl Physiol 2004;93:183-9.

11. Granata KP, Gottipati P. Fatigue influences the dynamic stability of the torso. Ergonomics 2008;51:1258-71.

12. Geusens P, Autier P, Boonen S, Vanhoof J, Declerck K, Raus J. The relationship among history of falls, osteoporosis, and fractures in postmenopausal women. Arch Phys Med Rehabil 2002;83:903-6.
13. Kuczyński M, Ostrowska B. Understanding falls in osteoporosis: the viscoelastic modeling perspective. Gait Posture 2006;23:51-8.

14. World Health Organization. (1994). Assessment of fracture risk and its application to screening for postmenopausal osteoporosis: Report of WHO Study Group (WHO Technical Report Series, No. 843). Geneva, Switzerland: Author. World Health Organization. (2003a).

15. Bicici S, Karatas N, Baltaci G. Effect of athletic taping and kinesiotaping ${ }^{\oplus}$ on measurements of functional performance in basketball players with chronic inversion ankle sprains. Int J Sports Phys Ther 2012;7:154-66.

16. Gribble PA, Tucker WS, White PA. Time-of-day influences on static and dynamic postural control. J Athl Train 2007;42:35-41.

17. Rasool J, George K. The impact of single-leg dynamic balance training on dynamic stability. Phys Ther Sport 2007;8:177-84.

18. Gribble PA, Kelly SE, Refshauge KM, Hiller CE. Interrater reliability of the star excursion balance test. J Athl Train 2013;48:621-6.

19. Munro AG, Herrington LC. Between-session reliability of the star excursion balance test. Phys Ther Sport 2010;11:128-32.

20. McGill SM, Childs A, Liebenson C. Endurance times for low back stabilization exercises: clinical targets for testing and training from a normal database. Arch Phys Med Rehabil 1999;80:941-4.

21. Chan YH. Biostatistics 104: correlational analysis. Singapore Med J 2003;44:614-9.

22. Earl JE, Hertel J. Lower-extremity muscle activation during the Star Excursion Balance Tests. Journal of Sport Rehabilitation 2001;10:93-104.

23. Robinson R, Gribble P. Kinematic predictors of performance on the Star Excursion Balance Test. J Sport Rehabil 2008;17:347-57.

24. Roghani T, Torkaman G, Movasseghe S, Hedayati M, Goosheh B, Bayat N. Effects of short-term aerobic exercise with and without external loading on bone metabolism and balance in postmenopausal women with osteoporosis. Rheumatol Int 2013;33:291-8.

25. Shirazi KK, Wallace LM, Niknami S, Hidarnia A, Torkaman G, Gilchrist M, et al. A home-based, transtheoretical change model designed strength training intervention to increase exercise to prevent osteoporosis in Iranian women aged 40-65 years: a randomized controlled trial. Health Educ Res 2007;22:305-17.

26. Lindle RS, Metter EJ, Lynch NA, Fleg JL, Fozard JL, Tobin J, et al. Age and gender comparisons of muscle strength in 654 women and men aged 20-93 yr. J Appl Physiol (1985) 1997;83:1581-7.

27. Sinaki M, Nwaogwugwu NC, Phillips BE, Mokri MP. Effect of gender, age, and anthropometry on axial and appendicular muscle strength. Am J Phys Med Rehabil 2001;80:330-8.

28. Hsu WL, Chen CY, Tsauo JY, Yang RS. Balance control in elderly people with osteoporosis. J Formos Med Assoc 2014;113:334-9.

29. Laughton CA, Slavin M, Katdare K, Nolan L, Bean JF, Kerrigan DC, et al. Aging, muscle activity, and balance control: physiologic changes associated with balance impairment. Gait Posture 2003;18:101-8. 
30. Abreu DC, Trevisan DC, Costa GC, Vasconcelos FM, Gomes MM, Carneiro AA. The association between osteoporosis and static balance in elderly women. Osteoporos Int 2010;21:1487-91.

31. Lynn SG, Sinaki M, Westerlind KC. Balance characteristics of persons with osteoporosis. Arch Phys Med Rehabil 1997;78:273-7.

32. Hammar ML, Lindgren R, Berg GE, Möller CG, Niklasson MK. Effects of hormonal replacement therapy on the postural balance among postmenopausal women. Obstet Gynecol 1996;88:955-60.

33. Gunend Z, Demirsoy N. Clinical and Computerized Stabilometrical Evaluation of Postural Balance in Postmenopausal Women with Osteoporosis. Turk J Phys Med Rehab 2007;53:130-3.

34. Korkmaz N, Tutoğlu A, Korkmaz I, Boyacı A. The Relationships among Vitamin D Level, Balance, Muscle Strength, and Quality of Life in Postmenopausal Patients with Osteoporosis. J Phys Ther Sci 2014;26:1521-6.

35. Hita-Contreras F, Martínez-Amat A, Lomas-Vega R, Álvarez P, Mendoza N, Romero-Franco N, et al. Relationship of body mass index and body fat distribution with postural balance and risk of falls in Spanish postmenopausal women. Menopause 2013;20:202-8.

36. Granacher U, Lacroix A, Roettger K, Gollhofer A, Muehlbauer T. Relationships between trunk muscle strength, spinal mobility, and balance performance in older adults. J Aging Phys Act 2014;22:490-8.
37. Emilio EJ, Hita-Contreras F, Jiménez-Lara PM, LatorreRomán P, Martínez-Amat A. The association of flexibility, balance, and lumbar strength with balance ability: risk of falls in older adults. J Sports Sci Med 2014;13:349-57.

38. Suri P, Kiely DK, Leveille SG, Frontera WR, Bean JF. Trunk muscle attributes are associated with balance and mobility in older adults: a pilot study. PM R 2009;1:916-24.

39. Cunha-Henriques S, Costa-Paiva L, Pinto-Neto AM, FonsechiCarvesan G, Nanni L, Morais SS. Postmenopausal women with osteoporosis and musculoskeletal status: a comparative cross-sectional study. J Clin Med Res 2011;3:168-76.

40. Miyakoshi N, Hongo M, Maekawa S, Ishikawa Y, Shimada Y, Itoi E. Back extensor strength and lumbar spinal mobility are predictors of quality of life in patients with postmenopausal osteoporosis. Osteoporos Int 2007;18:1397-403.

41. Mika A, Fernhall B, Mika P. Association between moderate physical activity, spinal motion and back muscle strength in postmenopausal women with and without osteoporosis. Disabil Rehabil 2009;31:734-40.

42. Parreira RB, de Oliveira MR, Amorim CF, Teixeira And DC, da Silva RA. Older adults present better back endurance than young adults during a dynamic trunk extension exercise. J Back Musculoskelet Rehabil 2014;27:153-9.

43. Champagne A, Descarreaux M, Lafond D. Comparison between elderly and young males' lumbopelvic extensor muscle endurance assessed during a clinical isometric back extension test. J Manipulative Physiol Ther 2009;32:521-6. 